\title{
Implementation of Conversation Instruction to Upgrade Speech Skill (A Comparative Study between Pondok Pesantren Walisongo Sragen and Pondok Pesantren Darul Mukhlisin Temulus Ngawi)/ تنفيذ تعليم

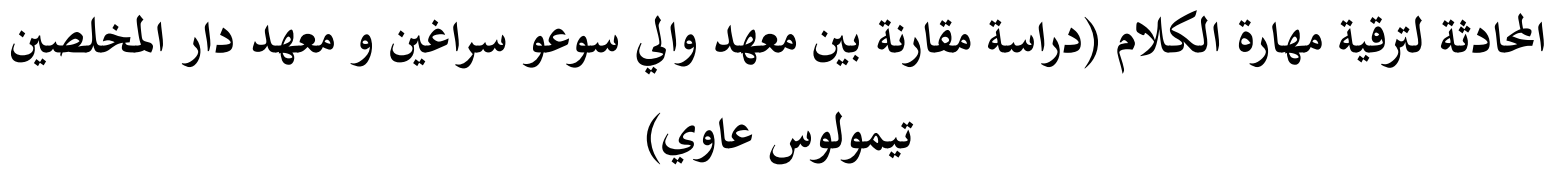

\author{
Rohmah Susilaningtyas \\ MAN 02 Sragen \\ rohmahtyas95@gmail.com
}

\begin{abstract}
This research aims to know: (1) explaining the history of Muhadasah program in boarding school Walisongo Sragen to increase Maharoh kalam in the year 2018/2019 (2) explaining the use of Muhadasah program in Walisongo Boarding School Sragen to increase Maharoh kalam in the year 2018/2019. This research uses qualitative research. The methods of collecting data are observations, interviews and documentation. The test validity of data by using source triangulation. The analysis of data starts with data collection, data reduction, data presentation and conclusion. The results showed that: 1) The Muhadasah Program is used to increase the Maharoh kalam this appears on the indicator of the students achievement in the Maharoh Kalam, the program begins from the Salaf boarding school that only teaches the kitab kuning then Develop a muhadasah program to enhance the Maharoh kalam. The level of learning of the nature of the boarding school Walisongo Sragen starts from the basic level and intermediate and the upper level. (2) The activities of the muhadasah program carried out every Sunday then implemented on the use of Arabic in daily conversation although the implementation of this program is a new program for the Salaf boarding school. Alhought, the model oflearning Muhadasah in the Waisongo boarding school Sragen by using memorization model, free muhadasah model and the model of the answer (dialogue). Alhought, method of evaluation is used with the observation approach and location approach.
\end{abstract}

Keywords: Implementation, Muhadasah Program

\begin{abstract}
Abstrak
Penelitian ini bertujuan untuk mengetahui: (1) Sejarah Program Muhadasah di Pondok Pesantren Walisongo Sragen dalam Meningkatkan Maharoh Kalam Tahun 2018/2019 (2) Penggunaan Program Muhadasah di Pondok Pesantren Walisongo Sragen untuk Meningkatkan Maharoh Kalam di tahun 2018/2019. Penelitian ini merupakan penelitian kualitatif. Metode pengumpulan data adalah observasi, wawancara dan dokumentasi. Uji validitas data dengan menggunakan triangulasi sumber. Analisis data dimulai dengan pengumpulan data, reduksi data, penyajian data dan penarikan kesimpulan. Hasil penelitian menunjukkan bahwa: 1) Program Muhadasah digunakan untuk meningkatkan maharoh
\end{abstract}


kalam hal ini terlihat pada indikator prestasi santri di maharoh kalam, program dimulai dari pesantren salafyang hanya mengajarkan kitab kuning kemudian mengembangkan program muhadasah. untuk meningkatkan kalam Maharoh. Tingkat pembelajaran alam Pondok Pesantren Walisongo Sragen dimulai dari tingkat dasar dan menengah serta tingkat atas. (2) Kegiatan program muhadasah dilaksanakan setiap hari minggu kemudian diimplementasikan pada penggunaan bahasa arab dalam percakapan sehari-hari walaupun pelaksanaan program ini merupakan program baru bagi pesantren salaf. Padahal, model pembelajaran Muhadasah di Pondok Pesantren Waisongo Sragen dengan menggunakan model hafalan, model muhadasah bebas dan model jawaban (dialog). Padahal, metode evaluasi yang digunakan dengan pendekatan observasi dan pendekatan lokasi.

Kata Kunci: Implementasi, Program Muhadasah

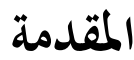

تعد مهارة الكلام من إحدى المهارات الأساسية، لأن اللغة الأصل كلام وقد نبه إلى ذلك إبن

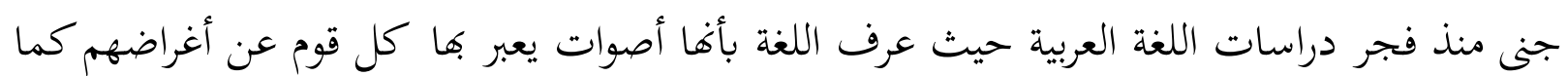

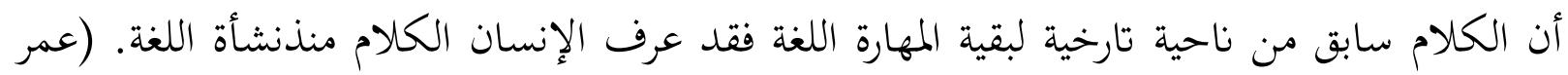

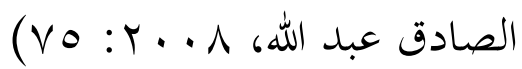

يعتبر الكلام الفن الثاني من فنون اللغة العربعة بعد الاستماع، وهو ترجمة اللسان عما تعلمه

الانسان عن طريق الاستماع والقراءة والكتابة، وهو من العلامات المميزة للإنسان فليس كل صوت

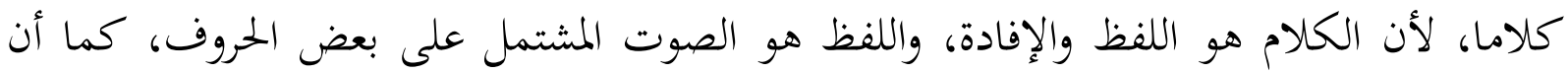
الإفادة هي :مادلت على معنى من المعاني، على الأقل في ذهن المتكلم. (أحمد فؤد محمود عليان، $(\wedge 0: r \cdot)^{\prime}$

استخدم الكلام للنشاط اللغوى للكبار والصغار على السواء، فالناس يستخدمون الكلام أكثر

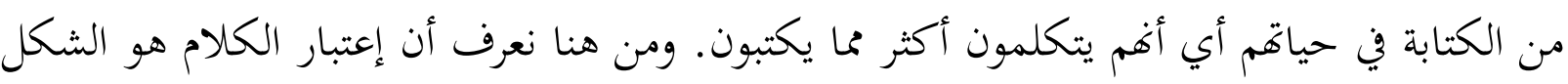
الرئسي للتصال اللغوي بالنسبة للإنسان. وفقا على هذا يعتبر الكلام أهم جزء في الممارسة اللغوية واستخدامتها.

توجد كثير من المؤسسة التربوية التى تحاول تطوير تعليم اللغة العربية وتنفيذ مهارة الكلام على

تلاميذهم بالطريقة المتنوعة بشكل تقليدي وشكل عصري. إضافة على ذلك تنفيذ الإندونسي اللغة

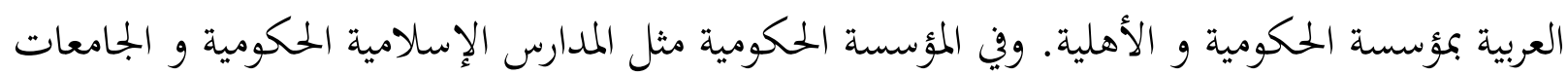


الإسلامية الحكومية و ايضا الجامعة الحكومية. ولا شك لكل منهم تعلم اربع مهارات اللغة فيها مهارة الكالام و الإستماع والقراءة والكتابة.

فضلا عن المؤسسة الحكومية ان اللغة العربية تدرس على المؤسسة الأهلية نحوى المعاهد و مساكن الطلبة و مساكن المكثف اللغة و إستمارة تعليم اللغة. و قد تحاول تطوير تعليمها بوسائل و الطرق المتنوعة بأسهل السبل حتى تؤدي إلى ضيع الوقت. وعى عدة المادية التى يتضمنها المؤسسة الأهلية كل ما يؤكد عليه علوم اللغة العربية و قواعدها بل في الحديث نشر تعلم اللغة العربية قواعدها و اكتساب مهارها الأربعة بأن لايكفي من تعلم اللغة من حيث قواعد وحدها بل إنما تكون بممارسة اللغة بين أهلها. وفي الحاضر كفاءة اللغة الأجنبية أمر مهم، اها شرط لدخول الجامعة محليا ام خارجيا و لكفائة المنحة الدراسية بدول العربي و فضلا على هذا كان الموظفون الإندونسية (TKI) م الذين أرسلهم الحكومة الى دول العربي مجهزة باللغة العربية. ومع هذا قد نعرف اهمية تعليم اللغة ليس بالموسسة الحكومية وحده بل انما بالموسسة الأهلية أيضا.

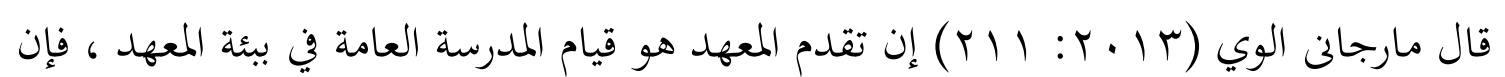
نوع المعهد هو نوعان، المعهد السلفي و المعهد الخلفى. والمعهد السلفي هو المعهد الذي تعلم به كتب التراث واما المعهد الخلفي هو المعهد الذي ينمى المدرسة العامة و ينمى المادة حيث الكتب التراث وحده. المعهد الخلفى هي الذي ينفيذ اللغة الأجنبية في برنامج التعليمى. اعتمدت هذه الخطة بسير الزمان و الثقافة على وجه ابتكار التعليم و لا يوثق بكتب و تعليم تقليدي. اضافة على روءسة محكام الرحمان أن المعهد الخلفى ينمي المادة العام في برنامج التعليم المعهد خلافا على المعهد السلفى الذي يركز على تعليم كتب التراث. ومن بعض مميزة المعهد السلفي هي استخدام تعليم Sorogan وbandongan، ومراجع التعليم يوجه الى كتب التراث وكتب العلماء المصنف محليا ام خارجيا. و اهداف تعليم اللغة العبية هي فهم كتب الترراث غالبا و تعويد حفظ القواعد اللغة العربية (النحو والصرف) . جانبا على ذلك فإن إهتمام هذا الممعهد في تعليم علوم الإسلام انتاج بكتب التراث. ومن البيان المذكور يؤكد الفرق بين مميزات المعهد الخلفى والسلفي و اكتساب المتخرجات المختلفة. وفن الغالب أن المتخرجين من المعهد الخلفى هم يقدرون اللغة الإنتاجية كلاميا و المعهد السلفي 
هم يقدرون في فهم نصص العربي كتب التراث. والمعهد والي سوعوا سراغين من احدى المعاهد السلفي

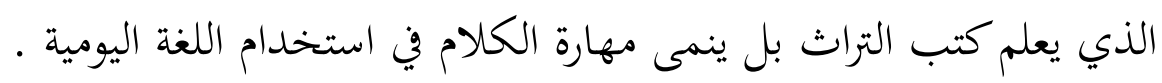
والمعهد والي سوعوا سراغين من احدى المعهد السلفي قيادة تحت رئاسة معروف اسلامودين سنة

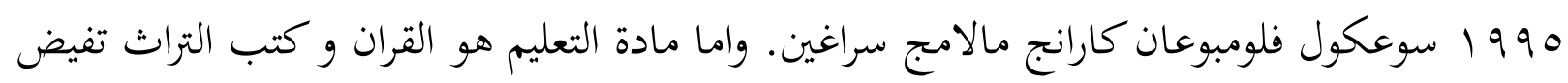

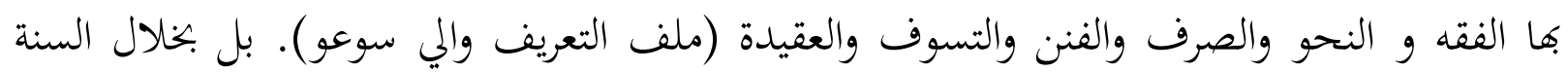
ع ا • r ينمي مهارة الكلام بطربقة المحادثة فيه. وهذه الحالة تكون المحادثة احدى البرامج الراجح بوسيلة بيئة اللغة في اكتساب اللغة.

بجانب على ذلك تطور المعهد السلفي في مانعان عاوي هو معهد دار المخلصين الذي ينفيذ

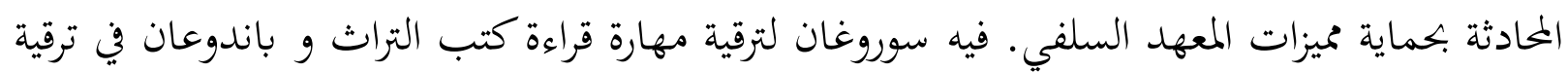
مهارة الإستماع و اجعل معني الكتاب في مهارة الكتابة. ولذلك تنفيذ المحادثة لترفقية مهارة الكلام.

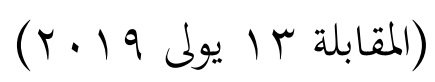
ان برنامج المحادثة ينظم ويوفر بالمدرسة المتوسطة المعهدية. هذه الحالة على اسس صميم الأساتيذ

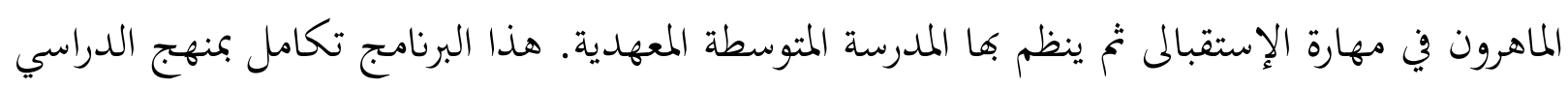
المعهد وقد تكون حصة التعلم بها على حصة التعليم الدينية المعهد. اها حصتان في الأسبوع. (المقابلة (r. ومن هذا اردت الباحثة ان تبحث عن تعليم المحادثة لترقية مهارة الكلام في معهد والي سوعوا سراغين ومعهد دار المخلصين تيمولوس عاوي مع ان في الغالب المعهد السلفي لاتنفيذ مهارة الكلام.

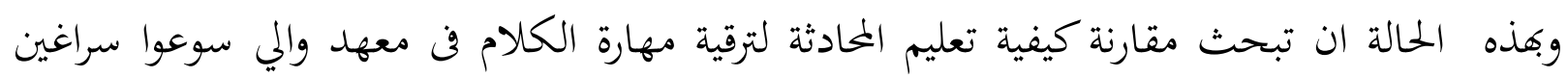
ومعهد دار المخلصين تيمولوس عاوي.

\section{منهج البحث}

طريقة البحث المستعملة فن هذا البحث هي بكثا وصفيا كيفيا. فموضوع هذا البحث هو التلاميذ

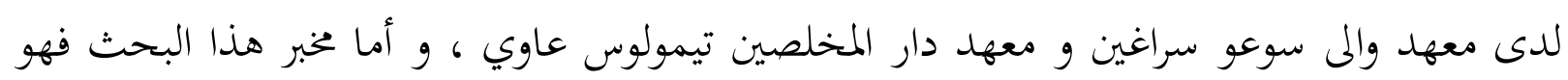
قسم اللغة ، و المشرفة، و رئيس المعهد و مدابر اللغة و الأستاذة. طريقة جمع البيانات الملاحظة والمقابلة 
والتوثيقية. وأما تصحيح البيانات بالتثليث ويتداء التحليل بجمع البيانات ويصير البيانات و تقديم البيانات ونتائج البيانات.

\section{نتائج البحث}

\section{تعليم المحادثة وأهدافها}

كلمة "المحادثة" هي اسم المصدر من فعل "حادث-يحادث-محادثة" بوزن "فاعل-يفاعل-مفاعلة"

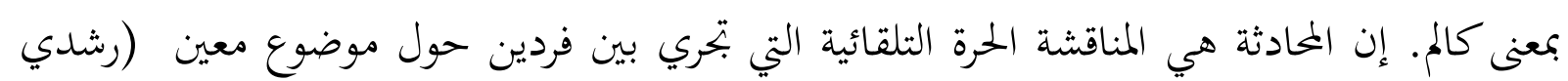

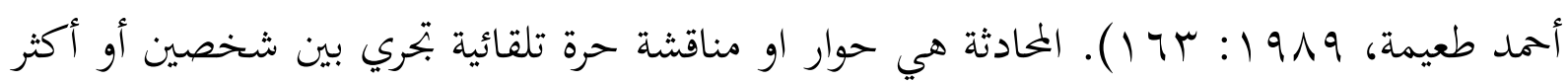
حول موضوع معيين وتقضي التفاعل ولا بد من أمرين هما تبنى فكرة خاصية بالفرد ذاته ومتابعه الأفكار

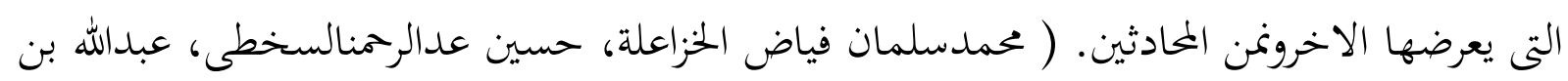

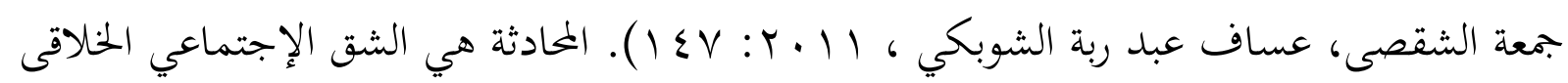

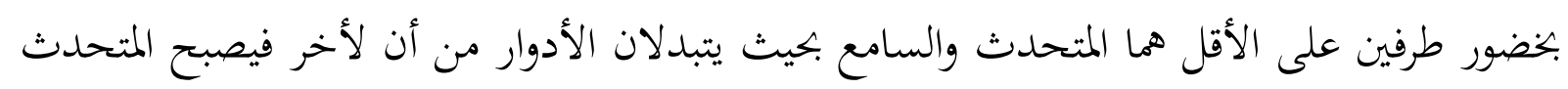

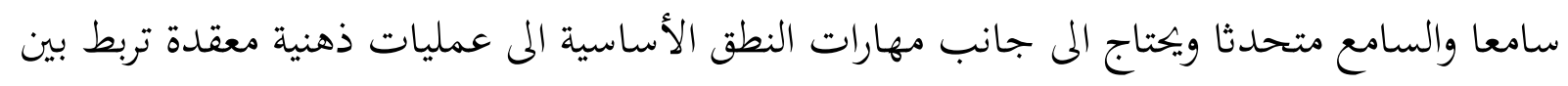
المعانى والتعبير الشفهى عنها وتغيير استجابته لمقتضيات موقف الإتصال بين المتحدثين. (عمر الصديق

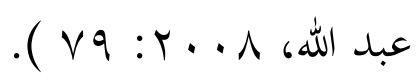

المحادثة (التعبير الشفهي) هي المنطلق الأول للتدرب على التعبير بوجه عام، و هو عبارة عن التخاطب

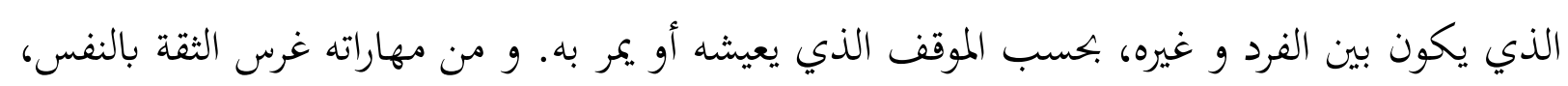

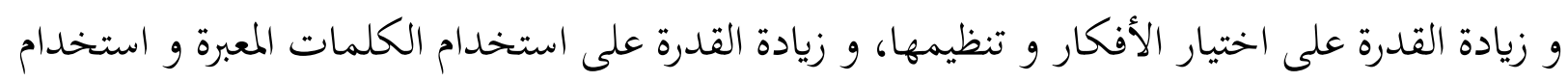

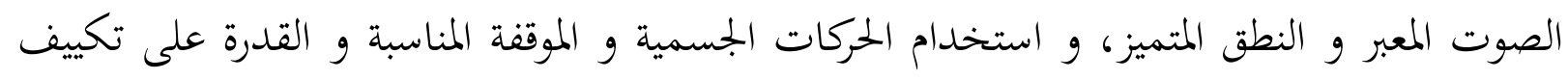

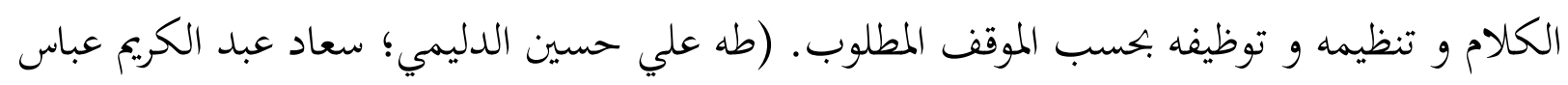

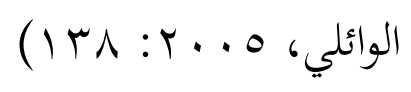

أن المحادثة هي من أهم ألوان النشاط اللغوي للصغار و الكبار. فإذا أضفنا إلى ذلك ما تقتضيه

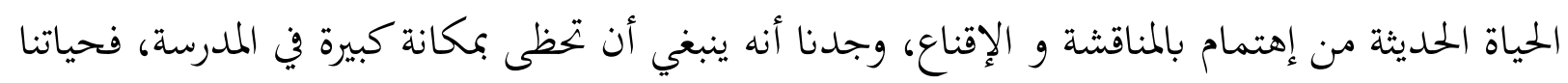

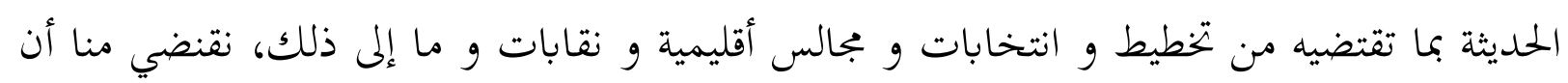


يكون كل فرد قادرا على المناقشة بحيث يستطيع أن يؤدي واجبه كعضو في مجتمع إسلامي حر (علي

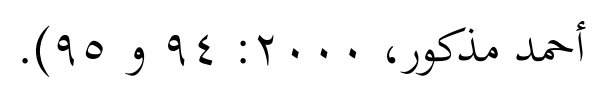

بناءا على التعريفات السابقة نعرف أن المحادثة هي نوع من أنواع النشاط اللغوي بحري بين شخصين اواكثر حول موضوع معين و يواصل بعضهم بعضا لقضاء حاجتهم.

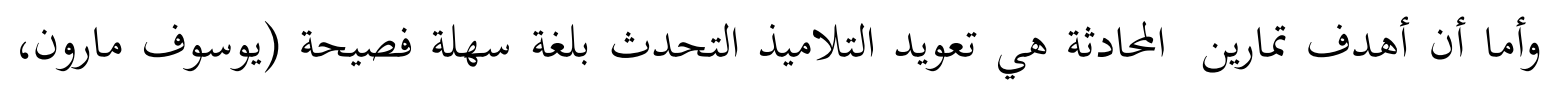

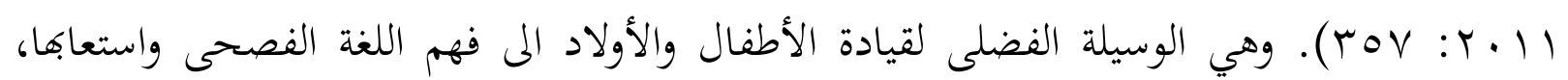
والتحدث بها بسهولة ويسر وترك اللغة المحكية واللهجات العامية التى يتكلمون بها في بيوقم ومدرستهم. هناك أهداف عدة يسعى مدرسوا اللغة العربية الي تحقيقها لدي التلاميذ من خلال تدريس المحادثة

1) رفد التلاميذ بحصيلة لغوية من الفردات والتراكيب والتعبيرات المختلفة التى تساعدهم في التعبير عما يجول في أذهاهم من المعانى والأفكار شفويا وتدريبهم على توظيف هذا المخزون اللغوي توظيفا

$$
\text { صحيحا فيما يناسبها من مجريات الحديث. }
$$

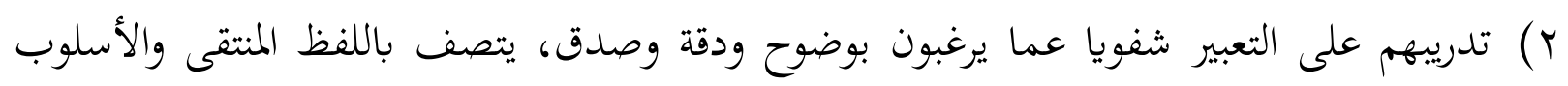

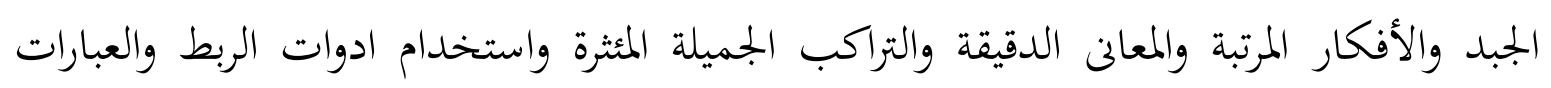
السليمة.

r) الإرتقاء بأواقهم الأدبية وأحساسيسهم الفنية وتدريبهم على الإحساس بجوانب الجمال في اللغة وانتقاء الكلمات العذبة والتعابير الجميلة والمعانى الجلديدة والأفكار السليمة. ع) تدريبهم على الخطابة ودفعهم المى المحادثة امام الأخري، وهذه المواقف تتطلب الإنهاء الإفصاح عما سرائرهم من أراء وافكار بوضوح وحرية. ه) اكتساب اللغة اكتسابا لأن اللغة تكتسب بالهرئ والسماع الى الأخرين ، وإن اللغة ينظر اليها عن طريق

$$
\text { الفم والأذن وليس عن طريق القلم والعين. }
$$

7) تعويد الطلبة اداب الحديث والإصغاء، واحترام أقوال الناس الذين يتحدثون اليهم بلغة سليمة جذابة ولئ وتعبيلار لأت مرغوبة اجتماعيا وحسنن عرض وجهة نظرهم واحترام اراء الأخرين بما يمكنهم من لتربن التكيف الإجتماعي. 


\section{خطوات تعليم المحادثة}

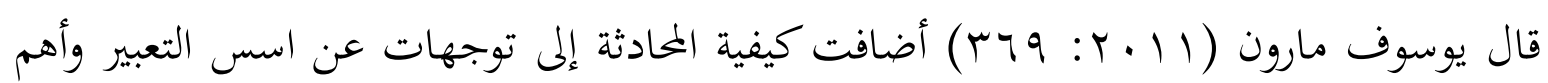

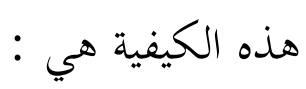

أن يلتزم المدرس التحدث باللغة العربية الفصيحة المبسطة، والمدرس الماهر لن تعجزه اللغة السليمة

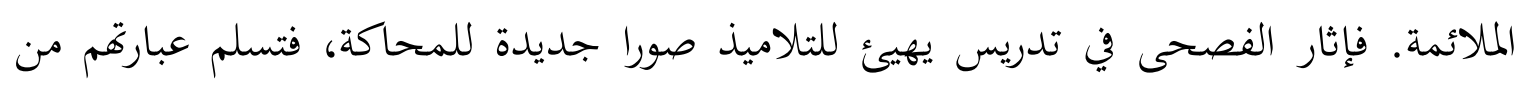
الصور العامية المبتذلة.

r المدم مقاطعاة التلميذ المتحدث لتصحيح أخطائه اللغوية وتأجيل التعليق او التصحيح الى ما بعد الواجب.

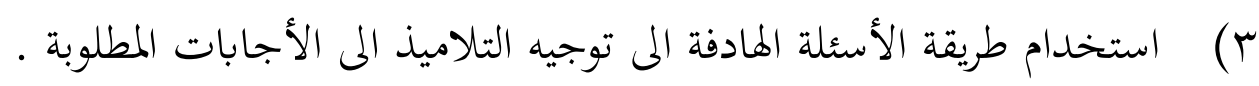
ع) يكلف المدرس كل المجموعة ، ترتيب الأسئيلة في كل نطقة وتدريب تلاميذه عنها.

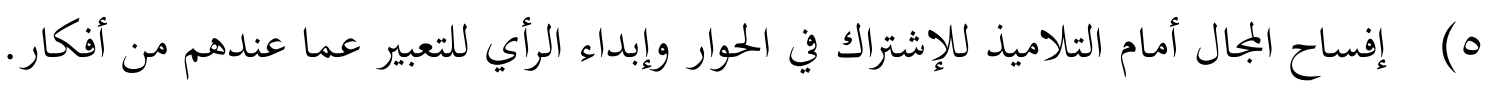

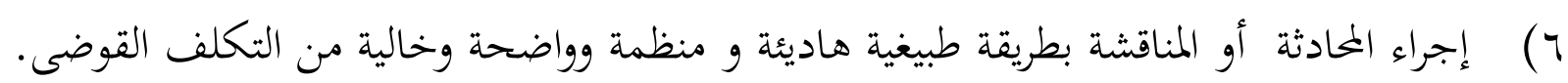

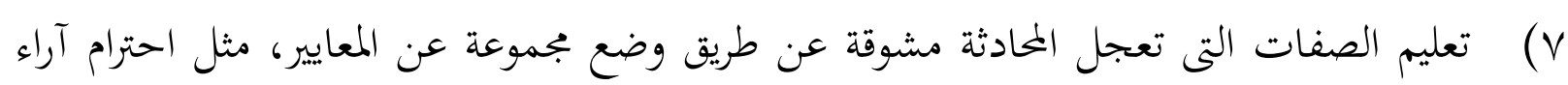

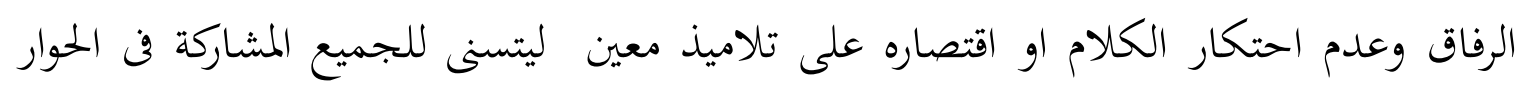
والمحادثة.

^) تزويد المدرسون بالكلمات الجديدة لكل موضوع بثروة لغوية تتناسب ومقدارتم ومستواهم

$$
\text { وعمرهم الزمنى. ألماء التلميذذ في جمل مفيدة و كلينمة مشتقة من جر الواحد }
$$

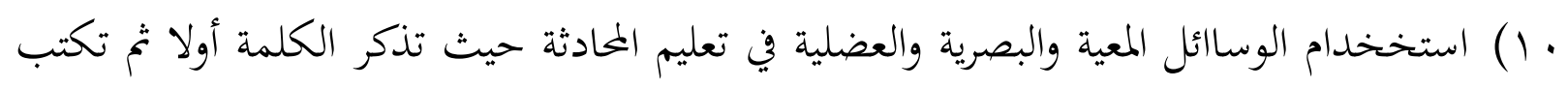

$$
\begin{aligned}
& \text { على اللوح وتنقل على دفاير. } \\
& \text { 1) (1) إصلاح الخطاء بصبر وهدوء والإبتعادعن الإنععال في أثناء الكلاماو الردا } \\
& \text { r T إدراء الحوار بلغة عربية فصيحة والتحدثمع التلاميذ بغصاحة فيجميعالمناسبات. }
\end{aligned}
$$




\section{مهارة الكلام وأهدافها}

إنّ المهارة هي مصدر من مهر - يمهر - مهارة. والمراد فيها الإستطاعة، وقد تطلق المهارة في فنون

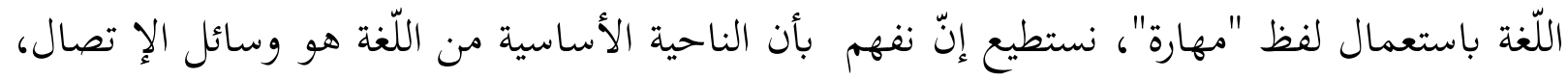

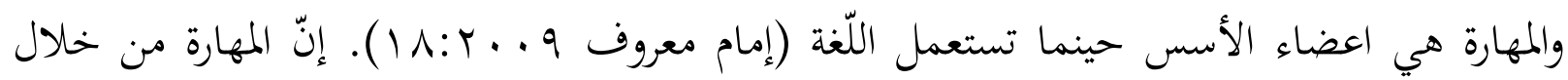

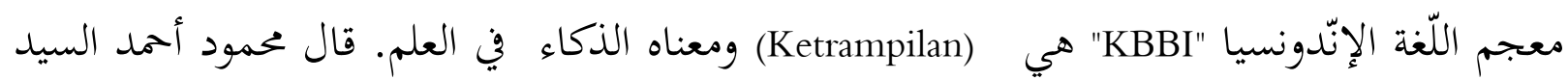

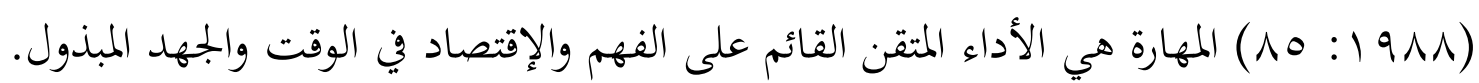
ترى التربية الحديثة أنّ المهارات اللغوية تتمثل في المحادثة والإستماع والقراءة و الكتابة (محمود أحمد العمداء السيد: 1911 : 1 1 ). وقال عبد الرحمن بن إبراهيم الفوزن تنقسم المهارة اللّغة الرئسية على أربع المهارات وهي مهارة الإستماع ومهارة الكلام ومهارة القراءة ومهارة الكتابة. فالكلام في أصل اللغة عبارة عن الأصوات المفيدة، وعند المتكلمين هو المعنى القائم بالنفس الذي يعبر عنه بألفاظ، يقال في نفسي

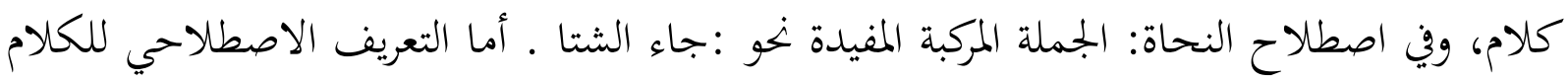
فهو :ذلك الكلام المنطوق الذي يعبر به المتكلم عما في نفسه من هاجسه، أو خاطره، وما يبهول بخاطره

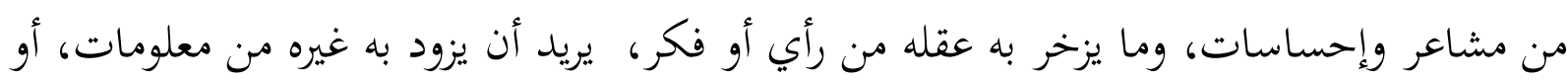

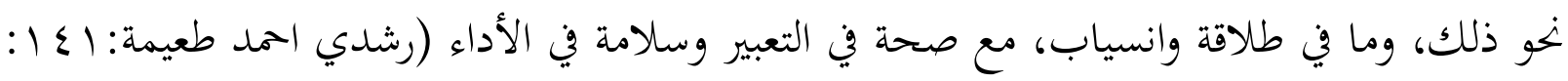
.$(17$.

وأما لمهارة الكلام أهداف عامة عاى مستوى البرنامج التعليمى المعين، كما لها أهداف خاصة ترتبط عادة بالصحة الدراسية ، ولكل نوع من هذين النوعين صياغة لغوية تختلف عنالأخرى وعلى المعلم

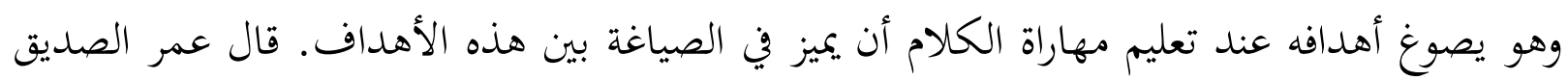

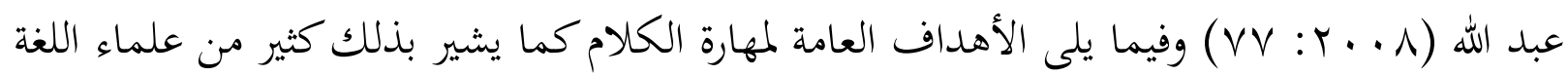
التطبقين : 20 - n

$$
\begin{aligned}
& \text { نطق الأصوات نطقا صحيحا } \\
& \text { التمييز عن النطق بين الأصوات المنشابهة تمييزا واضحا } \\
& \text { التمييز عند النطق بين الحركات القصيرة وبين الحركات القصيرة } \\
& \text { تأدية أنواع النبر والتنغيم بطريقة مقبولة من متحدثى العربية } \\
& \text { نطق الأصوات المتجاورة نطقا صحيحا }
\end{aligned}
$$


ATHLA : Journal of Arabic Teaching, Linguistic And Literature, 1, (1), 2020

التعبير عن الأفكار واستخدام الصيغ النحوية المناسبة

استخدام التعبيرات المناسبة للمواقف المختلفة

ترتيب الأفكار ترتيبيا منطقيا يلمسه المستمع

التحدث بشكل متصل ومرابطة لفترات زمنية مقبول مما ينبئ عن ثقة بالنفس وقدرته على مواجهة

الآخرين.

• (1) التركيز عند الكلام على المعنى وليس على الشكل اللغوي الذي يصوغ فيه هذا المعنى.

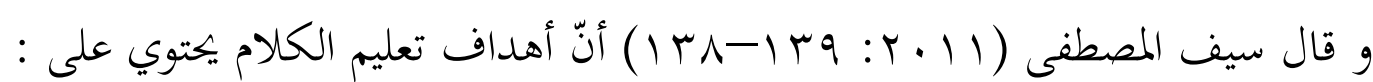

$$
\text { ( ) سهولة الكلام }
$$

في هذا الحال لابدّ التلاميذ في نيل الفرصة لتكلّم حتّى هم يقدرون في تقوية هذه المهارة بسهل و بمسرور، إمّا في المجموعة الصغيرة أو في المجموعة الكبيرة.

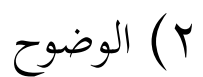

المراد بهذا الحال يجب التلاميذ يتكلّم باللغة تماما و واضحا، إمّا في الأسلوب أم في النطق.

$$
\text { r) مسؤول }
$$

تدريب التكلّم الصحيح يؤّمد المتكلّم ليكون مسؤول في التكلّم تماما و يذّّر جيدا عن الموضوع

$$
\text { ع) تشكيل المسموع الدقيق ابحثه، و غرض التكلّم و بمن يتكلّم و كيف الحال حين إذٍ. }
$$

ين هذا الحال يستطيع في تقوية المهارة الإستماع تماما و دقيقا يكون غرض الخاص في عمليّة التعليم.

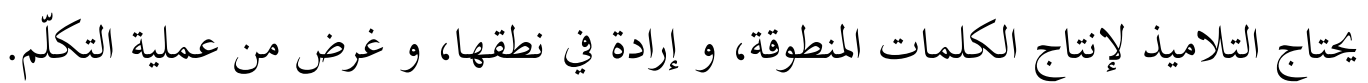

$$
\text { 0) تشكيل العادّة }
$$

لا يكون عادة التكلّم اللغة العربية إلّا بالإرادة التلاميذ. سوف ينجح هذه العادّة بالتعامل بين

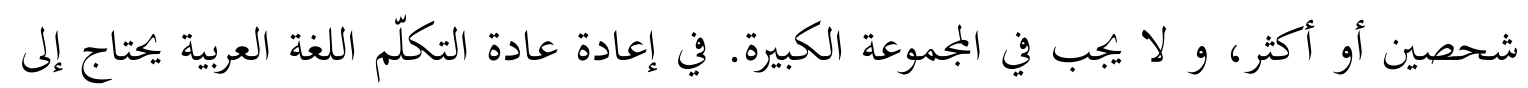

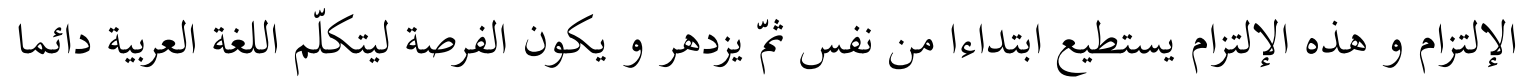

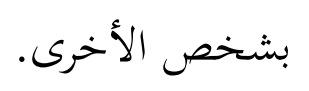




\section{مستويات مهارة الكلام}

قال رشدي أحمد طعيمة (919 19 بال 1) أنّ مستويات تعليم الكلام ينقسم إلى ب مستويات،

$$
\text { (1) كمايلي : المستوى الإبتدائي }
$$

يقصد هنا يمكن أن تدور مواقف الكلام حول أسئلة يطرحها المعلّم و يجيب عليها التلاميذ.

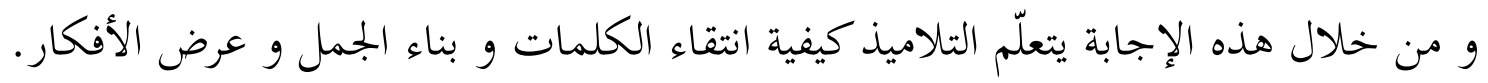

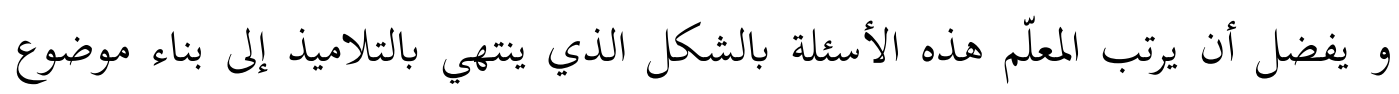

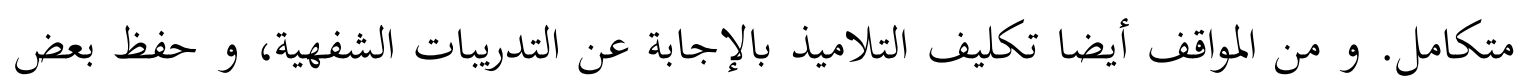

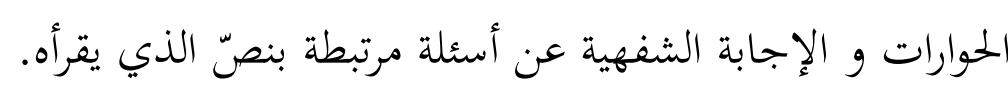

$$
\text { المستوى المتوسّط }
$$

يقصد هنا يرتفع مستوى المواقف التي يتعلّم التلاميذ من خلالها مهارة الكلام. من هذه التهائ.

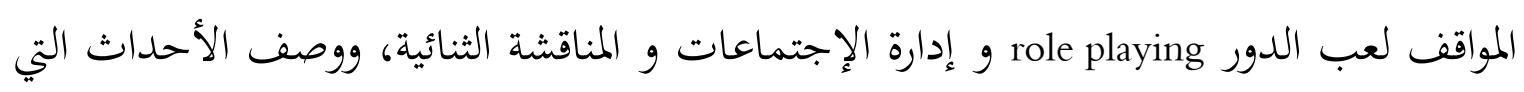

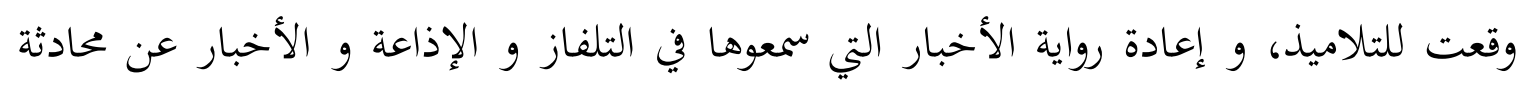

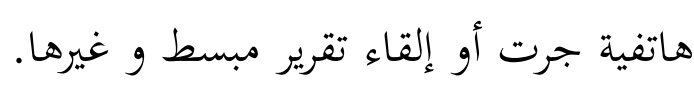

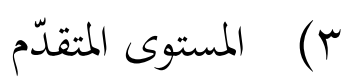
يقصد هنا قد يجكي التلاميذ قصة أعجبتهم، أو يصفون مظهرا من مظاهر الطبيعية. أو يلقون

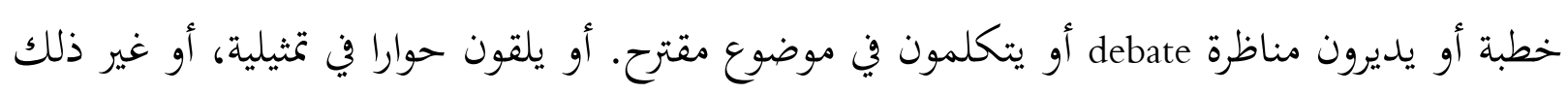
من مواقف.

\section{المعهد الإسلامي و أنواعه}

كلمة المعهد مأخوذة من كلمة فندوق بمعنى المسكاعه انمان. فمن القاموس الإندونسي انه هو بنيان

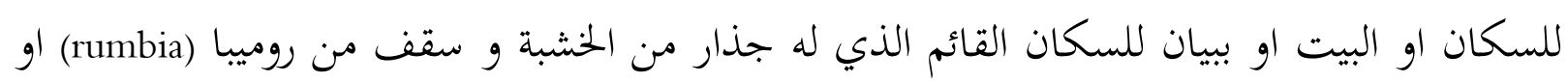

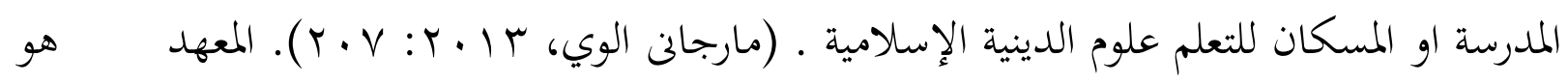

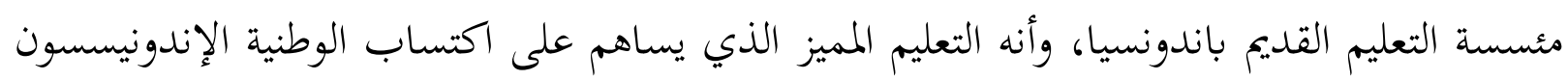

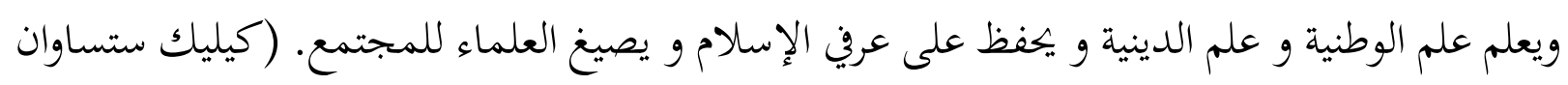




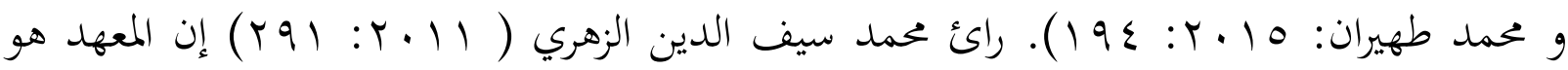
مؤسسة تربية إسلامية يخلط عرفي المجتمع الإندونسي. وأنه يميز بمحاولة ذكية الشعب و يعلم التعليم مدة رهمي

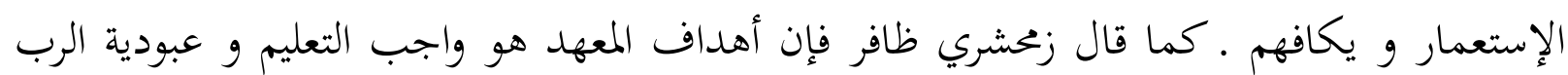
ليس إلتحاق على السلطة و الفلوس الشهادة و امور الدنيوي. ومع ذلك إصطلاح المعهد معروف قبل سنة . 97 1 م، بالنسبة الى اصتلاح فيسانترين (pesantren).

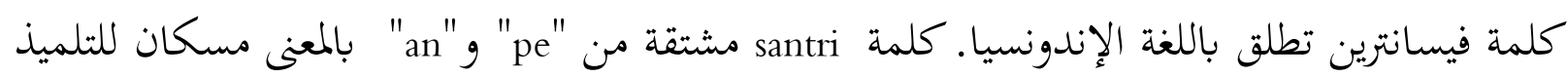
santri

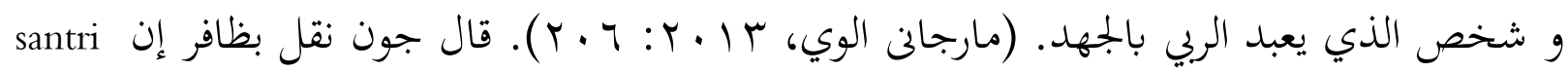

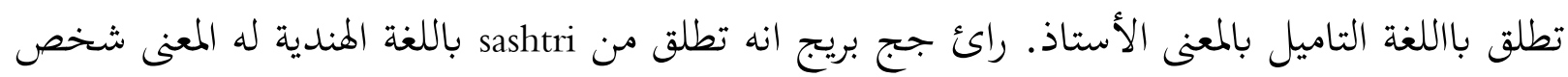

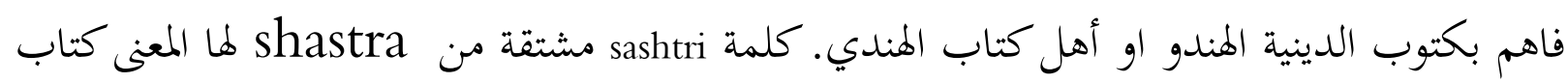

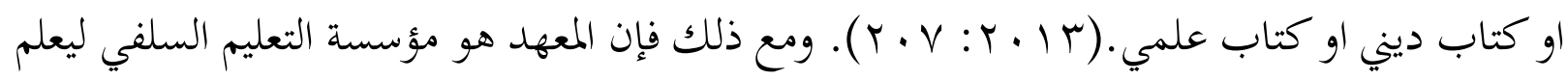

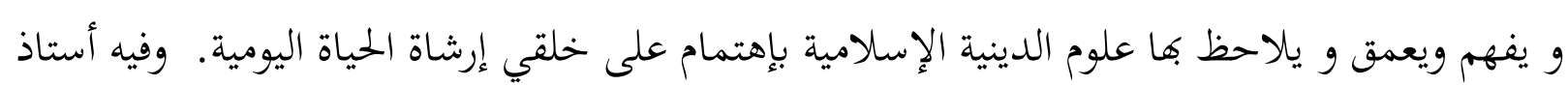
و تلميذ (kantriyai) و و و وسكان و و حجرة للتعليم و المسجد استخداما للمركز التعليم. جاء المعهد على المجتمع كمؤسسة التعليم و الدعوة الإسلامية. مع هذا دار انه يحارب الإستعمار واضحا الى مؤسسة بيلاندا سنة 1M 1 ا م كحرب كياهي موجو في تيجال ريهو و كيهي رفاعي في

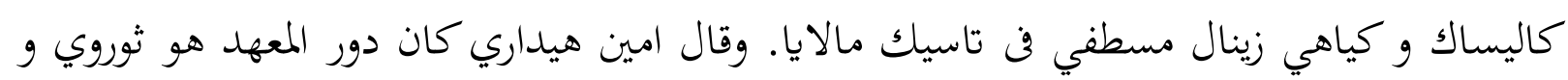

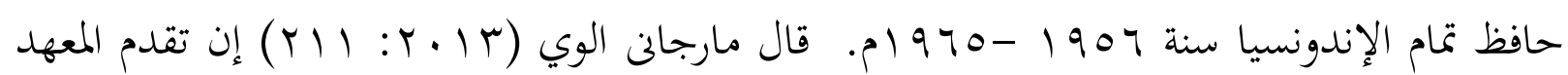
هو قيام المدرسة العامة في بيئة المعهد ، فإن نوع المعهد هو نوعان، المعهد السلفي و المعهد الخلفى. والمعهد السلفي هو المعهد الذي يعلم به كتب التراث واما المعهد العصري هو المعهد الذي ينمى المدرسة العامة و ينمى المادة حيث الكتب التراث وحده. والمعهد السلفي هو مئسسة تعليمية الذي يعلم به الأستاذ (كياهي) علوم الدبينية بكتب التراث باستخدام طريقة تقليدية كما بسوروغان و باندوعان و الحفاظ و المذاكرة دون الطرائق العصرية والملائمة

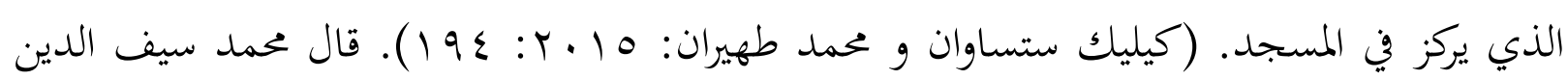

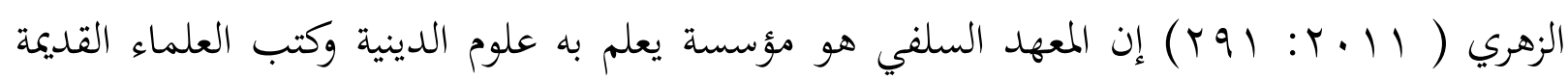
بطريقة سوروغان و باندوعان و الحفاظ و المذاكرة و المشاورة . 
وإن المعهد الخلفى هو مؤسسة تعليمية الذي يعلم به درس اللغة العربية والإنجيليزية في منهج الدراسية. اعتمد هذا المعهد بتقدم الثقافية والتربية دون التعليم التقلدية وحدة. (0 • ). قال عريف سبحان (q . . r : 19) فإن المعهد الخلفى هو المعهد الذي استخدام صيغة التعليم الجلديد. يعطى هذا المعهد حصة درس التعليم العام و قيام له في الفصول. وليست مراجع التعليم كتب التراث بل انما هي من كتب الجديد المكتوب بمؤلف الكتب الإسلام عهد . r. .

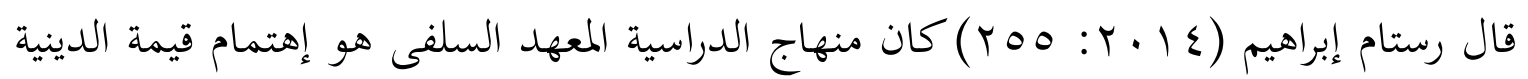
والسلفى ومطواع الأستاذ (kyai) و ممارسة الإخلاص. ومصادر المادة من كتب التراث ومن بعض الكتب المستعملة هي علم النحوى و وعلم الصرف و علم البلاغة و القرآن وعلومه والتفسير و الحديث و مصطلاحه وعلم التجود و علم التوحيد و علم الأخلاق و التاريخ وعلم الفقه واصوله. وقال دهاري

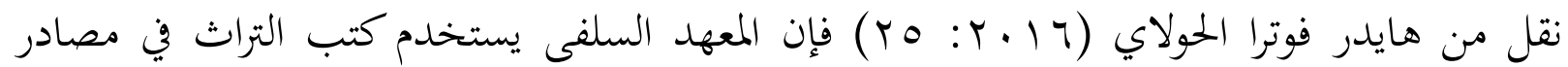
التعليم. وطريقة التعليم فيه بطرية سوروغان و ويتونان وتقيم التعليم بكفاءة التلميذ على كتب المقروء. والمادة العامة لا يعلم فيه ولا إهتمام دور الشهادة للبحث العمل بل إنما الإهتمام يكون في ملاحظة علوم الدينية حسب كتب التراث.

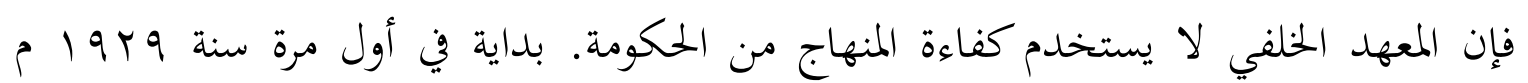
يستخدم المعهد الخلفى المنهاج من تلقاء نفسه ومع ذلك لا يكون الإمتحان النهائي الوطني • ورغم أن الشهادة محلي بل معتمد بالجامعة الأزهار الشريف. (قال عريف سبحان (و . . ب : م • 1). كان المعهد الخلفي يتقدم المنهاج التليم نفسا و ان يتكامل الوسائل التعليم و المكتبة تعد بعض الكتب العصرى و المجالات و ومايل المنظمة والرياضة و الإنترنبيت و تكوين المادة الملائمة للتنمية كفاءة النفس حيث ناحية والتفكير والعلمية والتكنولوجى. (عبد الطالب، 0 ـ ب : بr7).

الخملاصة

بناء على الدراسات السابقة و تحليلات على المعلومات و المالاحضات على الواقع، يستنتج هذا البحث إلى النتيجة منها : 
ا. ـ كان تنفيذ برنامج المحادثة في معهد والي سوعو سراغين ومعهد دار المخاصين تيمولوس عاوي نشأ من المعهد السلفي الذي يعلم به كتب التراث ثم ينمي برنامج المحادثة لترقية مهارة الكلام. والمستويات التعليم في معهد والي سوعو سراغين يتطور من المستوي الإبتدائ المى المستوى المتقدم. و اما المعهد دار المخلصين تيمولوس عاوي يتطور من المستوي الإبتدائ الى المستوي المتوسط. r. أن عملية تعليم المحادثة في معهد والى سوعو سراغين يمارس بها تفاعلا و تنفيذ ها في بيئة اللغة. اشكال تعليم المحادثة المستخدمة هي حفظ المحادثة و المحادثة الحورة و السؤل والجواب فأما اساليب التقويم المستخدمة هي مدخل الملاحظة و المدخل البنائي. واما معهد دار المخلصين تيمولوس عاوي يمارس برنامج المحادثة كفاء. اشكال تعليم المحادثة المستخدمة هي حفظ المحادثة و السؤل والجواب وطريقة المباشرة. فأما اساليب التقويم المستخدمة هو مدخل الملاحظة و المدخل البنائي. 


\section{المراجع}

رشدي أحمد طعيمة. تعليم العربية لغير الناطقين بها. مصر: المنظمة الإسالامية للتربية و العلوم و الثقافة-

$$
\text { إيسيسكو. }
$$

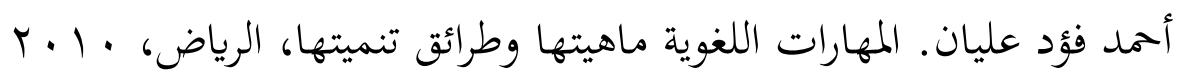

طه علي حسين الدليمي؛ سعاد عبد الكريم عباس الوائلي. الطرائق العملية في تدريس اللغة العربية. لأردن: دار الشروق. r. . ب.

$$
\text { علي أحمد مدكور. تدريس فنون اللغة العربية. القاهرة: دار الفكر العربي. . . .ب. }
$$

محمد سلمان فياض الخزاعة ، عبد الله بن جعة الشقصى، حسين عبد الرحمن السخنى، عساف عبد ربة الشوبكى. الإستراتيجيات التربوية ومهارات الإتصال التربوبي. عمان : دار صفاء للنشر والتوزيع. $\cdot+11$

مايك ليفي، جلين كويل. أبعاد تعلم اللغة بمساعدة الحاسوب الآلي (Call) خيارات وموضوعات في تعلم اللغة بمساعدة الحاسب الآلي. الرياض : النشر العلمى والمطابع. • 1 • ب.

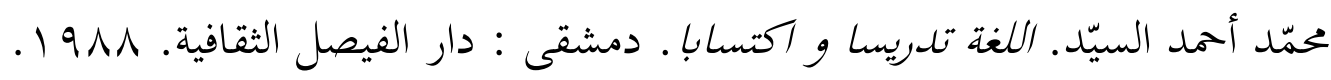
أحمد ورصان المنور. قاموس المنوّر. سورابايا: فوستاكا فروكريسيف. ب . . r.

محمد محمد داود. طريقة اسمع وتكلم نظرية ي بناء القدرة اللغوة لاكتساب مهارة الكلام. 1 ا • r. عمر الصديق عبد الله. تعليم اللغة العربية للناطقين بغيرها الطرق-الأسالب - الوسائل. الهرم : الدار العالمية

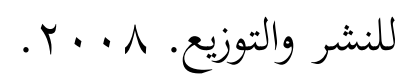

Abdul Thholib. Pendidikan Pondok Pesantren Modern. Risalah, 63.2015.

Arief Subhan. Lembaga Pendidikan Islam Indonesia Abad Ke-20. Jakarta: Uin Jakarta Press. 2009.

Dalhari. Pola dan Keragaman Pendidikan Islam (Kajian Tentang Pesantren Dan Ruang Lingkupnya). Al-Ibtida' Vol.4, Nomor 2.2016.

Imam Makruf. Strategi Pembelajaran Bahasa Arab Aktif. Semarang: Needs Press. 2009 
Kelik Stiawan, M. Tohirin. Format Pendidikan Pondok Pesantren Salafi Dalam Arus Perubahan Sosial di kota Malang. Cakrawala. Vol.X Nomor 2.2015.

Marjani Alwi. Podok Pesanren : Ciri Khas, Perkembangan dan Sistem Pendidikan. Lentera Pendidikan vol.16 Nomor 2 : 205-219.2013.

Mohammad Arif. Pondok Pesantren Salaf Transformatif. Al-Hikmah, Volume 1, Nomor 2.2011.

Rustam Ibrahim. Eksistensi Pesantren Salaf di Tengah Arus Pendidikan Modern. Analisa Vol.21 Nomor 2 :253-263.2014.

Sugiono. Metode Penelitian Kuantitatif Kualitatif Dan R\&D. Bandung: Alfabeta. 2008.

Syaiful Mustofa. Strategi Pembelajaran Bahasa Arab Inovatif. Malang: UIN Maliki Press. 2011.

Lexy J Moeleong. Metode Penelitian Kualitatif. Bandung: PT. Remaja Rosdakarya. 2010. 
ATHLA : Journal of Arabic Teaching, Linguistic And Literature, 1, (1), 2020

16 | Rohmah Susilaningtyas : Implementation of Conversation Instruction.... 